as the presence of extra organisers in polyploid and aneuploid plants results in extra nucleoli and a proportionate increase in $\mathrm{RNA}^{8,9}$.

Many of these examples can be repeated in terms of amplification, so it is only reasonable to suppose amplification is regulated in a similar manner to that outlined above for transcription. Macgregor ${ }^{1}$ argues to the contrary, but lacks evidence; his observations on polyploid oocytes are ambiguous on this point and I doubt if his results on spermatocytes are even pertinent.
Similarly, when applied to polytene chromosomes, Macgregor's hypothesis is only a possible but unnecessary complication to the control mechanism envisaged by Spear and Gall ${ }^{10}$.

$$
\text { H. Wallace }
$$

Department of Genetics,

University of Birmingham,

Birmingham, B15 2TT

1 Macgregor, H. C., Nature, 246, 81-82 (1973).

2 Wallace, H., J. Morphol., 112, 261-278 (1963).
${ }^{3}$ Wallace, H., Nat. Cancer Monogr., 23, 425-430 (1966).

4 Miller, L., and Gurdon, J. B., Nature, 227, 1108-1110 (1970).

${ }^{5}$ Wallace, H., and Langridge, W. H. R., Heredity, 27, 1-13 (1971).

6 Bramwell, M. E., and Handmaker, S. D. Biochim. biophys. Acta, 232, 580-583 (1971).

' Honjo, T., and Reeder, R. H., J. molec. Biol., 80, 217-228 (1973)

${ }^{8}$ Lin, M., Chromosoma (Berl.), 7, 340370 (1955).

${ }^{9}$ Longwell, A. R. C., and Svihla, G., Expl. Cell Res., 20, 294-312 (1960).

10 Spear, B. B., and Gall, J. G., Proc. natn. Acad. Sci. U.S.A., 70, 1359-1363 (1973).

\title{
obituary
}

\section{C. A. Ferraro}

V. C. A. Ferraro, who died on January 3, 1974, had been Professor of Applied Mathematics at Queen Mary College, University of London, since 1952; he expected to retire from his chair later this year. He had earlier (1947-52) been professor at the University of Exeter.

When he came to Queen Mary College the Department of Mathematics had six members; there are now three separate departments of Pure Mathematics, Applied Mathematics, Computer Science and Statistics, with a total of thirtyfive lecturing staff. Professor Ferraro directed this expansion with energy and foresight, encouraging the growth of algebra, magnetohydrodynamics and astrophysics, the theory of computation and statistics.

He was best known for his share in the Chapman-Ferraro theory of magnetic storms, and for his discovery of the law of isorotation in cosmic masses. The Chapman-Ferraro theory was first advanced in 1930, when Ferraro was a research student, and he returned to develop aspects of it over many years. The theory ascribed magnetic storms to streams emitted from the Sun into otherwise empty space, and the recognition that the solar wind flows all the time has meant that considerable modifications have later proved necessary. Moreover, the theory was a theory of the initial phase of a storm only; the type of ring current required to explain the main phase was not identified until much later. The essentially valuable new idea introduced in the theory was in its recognition that a solar stream must be regarded not as a collection of individual particles, but more nearly as a perfectly conducting fluid, able to modify the geomagnetic field by pushing the field-lines in front of it. The theory also introduced the idea of a magnetospheric cavity, though a temporary one.

The law of isorotation (1937), later much used in the theory of star formation, asserts that in a cosmic rotating mass of ionised gas penetrated by a magnetic field the angular velocity rapidly tends to become constant along a magnetic field line. This result, like those of the theory of magnetic storms, seems today an almost obvious illustration of the principles of magnetohydrodynamics (MHD). But these principles were not understood when Ferraro made his discovery; he can fairly be claimed to be one of the pioneers of MHD.

In the postwar years Ferraro did much to encourage research in MHD, by his own example, by organising regular seminars and by the writing of a book on the subject with Plumpton (1961). He also is known for his book on Electromagnetic Theory (1953). He was a person of continuous activity; this activity was a little circumscribed after a heart attack in 1965 , but he was publishing papers on the solar wind and related subjects up to the end.

But he will be remembered most in the College for his old world charm and personal courtesy, which is best conveyed in the words of one of Queen Mary College's cockney waitresses "He was a real gentleman, he was".

He leaves a widow and one son.

\section{Announcements}

\section{Awards}

The Trustees of the Lady Tata Me. morial Trust invite applications for Fellowships and Scholarships for research on leukaemia, in the Academic Year beginning October 1, 1974.

The prizewinners of the Feldberg Foundation awards for 1974 are Professor G. R. Brindley FRS, Honorary Director of the MRS Neurological Prostheses Unit, at the Institute of Psychiatry, and Professor P. Karlson, PhysiologischChemisches Institut der Universtat, Lahnberge.

\section{Errata}

In the article 'Effect of Muscle Stretching on Tension Development and Mechanical Threshold during Contractures' by H. Gonzalez-Serratos, R. Valle and A. Cillero (Nature new Biol., 246, 221; 1973) paragraph 10 , line 2 should read 'depolarisations produced with solutions containing 80 to $190 \mathrm{nM} \mathrm{K}{ }^{\circ}$...'. Reference 2 should read volume 117 not 177.
In the article "The Fluorescence of Quinacrine Mustard with Nucleic Acids' by Ritva-Kajsa Selander and Albert de la Chapelle (Nature new Biol., 245,$240 ;$ 1973) the labelling to the ordinate of Fig. 4 should read 'Fluorescence units at $514 \mathrm{~nm}$ ' not 'Fluorescence at $514 \mathrm{~nm}(\mathrm{~F})^{\prime}$. In Table 1 the heading of columns 2 and 3 should read 'Fluorescence units at $514 \mathrm{~nm}$ ' not 'Fluorescence $(F)$ at $514 \mathrm{~nm}$ '. The last sentence in the legend to Table 1 beginning 'Fluorescence was expressed .. .' should be deleted. The name of the first author should be Ritva-Kaisa Selander. 